\title{
KEMAMPUAN PEMECAHAN MASALAH SISWA SMA PADA HUKUM ARCHIMEDES
}

\author{
Rudi Purwanto \\ STIT Palapa Nusantara \\ rudipurwanto090992@gmail.com
}

\begin{abstract}
The purpose of this study was to explore the students' problem solving skill to solve problem in Archimedes principle on the senior high school level. The method of this study was mixed method with explanatory follow up explanation design. The subject of this study was 30 students of k-11 in SMAN 9 Malang. The kuantitative data was collected through survey by 2 essay questions with reliability cronbah alpha 0,70. The qualitative data was collected through interview after analyze student answare. The aim of this interview was to follow up the pattern of student answare. The result of this study shown that students' expert attitude began solve problem through definite problem qualitatively. In addition, the students' novice attitude refer to not describe a problem qualitatively.
\end{abstract}

Keywords: Problem solving skill; Archimedes' Law

\begin{abstract}
Abstrak: Tujuan penelitian ini adalah untuk mengeksplorasi kemampuan pemecahan masalah siswa dalam memecahkan masalah hukum Archimedes pada tingkat SMA. Jenis penilitian ini mixed methods desain explanatory Follow-up explanations model. Partisipan penelitian ini 30 siswa kelas XI SMAN 9 Malang. Data kuantitatif dikuumpulkan melalui survey dengan menyebarkan 2 butir test pemecahan masalah berbentuk essay denga reliabilitas alpha cronbah 0,70 . Sedangkan data kualitatif dikumpulkan melalui wawancara setelah menganalisis jawaban siswa untuk tindak lanjut pola-pola jawaban siswa. Hasil penelitian menunjukkan perilaku expert mulai memecahkan masalah dengan mendeskripsikan masalah secara kualitatif. Sedangkan novice cenderung tidak mendeskripsikan masalah secara kualitatif.
\end{abstract}

Kata Kunci: Kemampuan Pemecahan Masalah; Hukum Archimedes

\section{PENDAHULUAN}

Kemampuan pemecahan masalah merupakan kemampuan siswa dalam menggunakan proses berpikir untuk memecahkan permasalahan melalui pengumpulan fakta-fakta, analisis informasi, menyusun alternatif pemecahan, dan memilih pemecahan yang efektif. ${ }^{1}$ Beberapa peneliti membedakan kemampuan

${ }^{1}$ (Dwi, Arif, and Sentot 2013)

PALAPA : Jurnal Studi Keislaman dan Ilmu Pendidikan

Volume 8, Nomor 1, Mei 2020; p-ISSN 2338-2325; e-ISSN 2540-9697; 17-28

https://ejournal.stitpn.ac.id/index.php/palapa 
pemecahan masalah siswa dalam dua tipe, yaitu expert dan novice. Siswa expert mulai memecahkan masalah dengan mendeskripsikan informasi masalah secara kualitatif dan menggunakan informasi tersebut untuk menentukan langkah-langkah pemecahan sebelum menulis persamaannya. ${ }^{2}$ Sedangkan siswa novice mulai memecahkan masalah dengan menuliskan persamaan yang sesuai dengan pernyataan pada informasi masalah dan lebih fokus pada nilai-nilai kuantitatif dalam informasi masalah seperti apa yang diketahui dan tidak diketahui. ${ }^{3}$

Selama ini fluida statis merupakan salah satu materi fisika yang masih sulit dipecahkan oleh siswa. ${ }^{4}$ Salah satu bahasan fluida statis yang masih sulit dipecahkan oleh siswa adalah hukum Archimedes. ${ }^{5}$ Oleh karena itu, kemampuan pemecahan masalah menjadi fokus utama beberapa peneliti selama dua dekade terakhir ini. ${ }^{6}$ Beberapa diantaranya yaitu Yin (2008) menemukan bahwa siswa kesulitan memecahkan masalah hukum Archimedes. ${ }^{7}$ Hal ini karena siswa menganggap semakin banyak air maka benda akan semakin mengapung. Selain itu siswa juga menganggap gaya apung sebanding dengan kedalaman fluida. ${ }^{8}$ Sementara Chen dkk (2013) menemukan bahwa banyak siswa kesulitan mengidentifikasi gaya yang diberikan zat cair pada objek, sehingga siswa kesulitan memecahkan masalah peristiwa terapung dan tenggelam pada hukum Archimedes. ${ }^{9}$ Beberapa faktor penyebab masalah tersebut diantaranya yaitu guru jarang melatih dan memfasilitasi siswa dalam memecahkan masalah, sehingga menyebabkan siswa kurang tertarik untuk belajar fisika dan menyebabkan penguasaan konsep siswa rendah, sehingga berdampak pada kemampuan siswa dalam memecahkan masalah. ${ }^{10}$

Berdasarkan kajian-kajian tersebut, maka perlu adanya penelitian untuk menggali perilaku-perilaku siswa dalam memecahkan masalah hukum Archimedes yang dapat membantu siswa memperkuat konsep-konsep dasar hukum Archimedes

\footnotetext{
2 (Ding et al. 2011)

3 (Rosengrant, Van Heuvelen, and Etkina 2009)

4 (Aini, Kusairi, and Diantoro 2017)

5 (Purwanto and Yuliati 2017)

${ }^{6}$ (Riantoni et al. 2017)

7 (Journal and Volume 2017)

8 (Wagner, Carbone, and Lindow 2014)

9 (Chen, Irving, and Sayre 2013)

10 (Erinosho 2013)
} 
sebelum berpindah ke materi selanjutnya. Oleh karena itu tujuan penelitian ini adalah untuk mengeksplorasi perilaku expert dan novice dalam memecahkan masalah hukum Archimedes pada tingkat SMA.

\section{METODE}

Jenis penilitian ini adalah mixed methods desain explanatory Follow-up explanations model. Partisipan dalam penelitian ini adalah siswa SMAN 9 Malang kelas XI IPA semester II tahun pelajaran 2018/2019. Data kuantitatif dikumpulkan melalui survey dengan menyebarkan 2 butir test pemecahan masalah berbentuk essay pada 30 siswa kelas XI IPA SMAN 9 Malang yang telah menempuh materi hukum Archimedes. Jawaban siswa dianalisis menggunakan rubrik pemecahan masalah dengan lima indikator, yaitu Useful description, Physics approach, Spesific application of physics, dan Logical progression. ${ }^{11}$ Sedangkan data kualitatif dikumpulkan melalui wawancara setelah menganalisis jawaban siswa untuk tindak lanjut pola-pola jawaban siswa perilaku expert dan novice pada materi hukum Archimedes. Hasil analisis data kuantitatif dan kualitatif kemudian diinterpretasi hasilnya untuk ditarik kesimpulan.

\section{HASIL DAN PEMBAHASAN}

Jawaban siswa dalam memecahkan masalah hukum Archimedes dianalisis secara statistik deskriptif. Adapun hasil statistik deskriptif disajikan pada tabel 1 yang menyatakan nilai skor minimum, skor maksimum, nilai rata-rata, dan standar deviasi.

Tabel 1 Statistik Deskriptif Kemampuan Pemecahan Msalah Siswa

\begin{tabular}{cc}
\hline Statistik & Nilai \\
\hline Minimum & 31,72 \\
\hline Maksimum & 90 \\
\hline Mean & 60 \\
\hline Standar Deviasi & 20,13 \\
\hline
\end{tabular}

11 (Docktor et al. 2016) 
Kemampuan pemecahan masalah siswa tidak hanya dilihat dari hasil analisis statistik deskriptif saja, akan tetapi juga dilihat dari perilaku siswa dalam memecahkan masalah hukum Archimedes. Penilaian perilaku siswa dilakukan secara pengkodean uraian jawaban siswa berdasarkan perilaku expert dan novice yang diperkuat dengan wawancara. Berikut disajikan presentase hasil pengkodean proses pemecahan masalah siswa dalam memecahkan masalah hukum Archimedes.

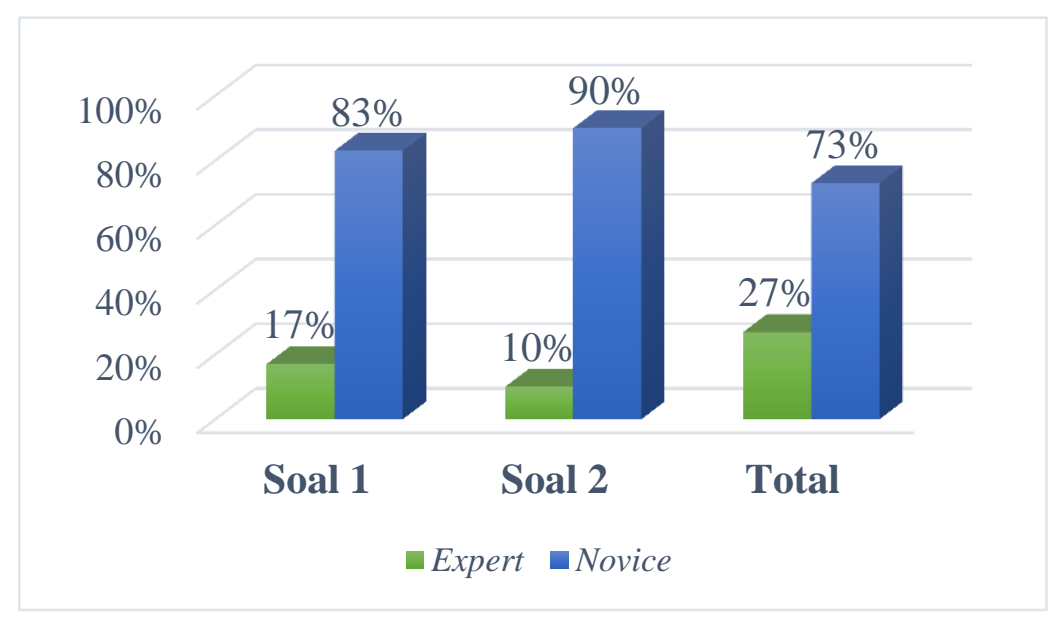

\section{Gambar 1 Presentase Siswa dalam Memecahkan Masalah Berdasarkan Perilaku Expert dan Novice}

Pada gambar 1 di atas, diketahui bahwa masih sedikitnya siswa dalam kategori expert dalam proses pemecahan masalah hukum Archimedes. Berdasarkan hasil pengkodean uraian jawaban siswa, ditunjukkan bahwa pada soal 1 terdapat $17 \%$ siswa dalam kategori expert dan 83\% siswa masih dalam kategori novice. Namun dari $17 \%$ siswa expert tersebut, hanya 10\% yang masih expert pada soal 2. Hal ini menunjukkan bahwa sebagian besar siswa masih kesulitan dalam menyelesaikan soal hukum Archimedes.

Adapun contoh soal 1 hukum Archimedes serta hasil pemecahan masalah expert problem solver dan novice problem solver ditunjukkan pada gambar 2. Pada soal tersebut, siswa diminta memecahkan permasalahan terkait dengan massa jenis dan gaya angkat ke atas. 


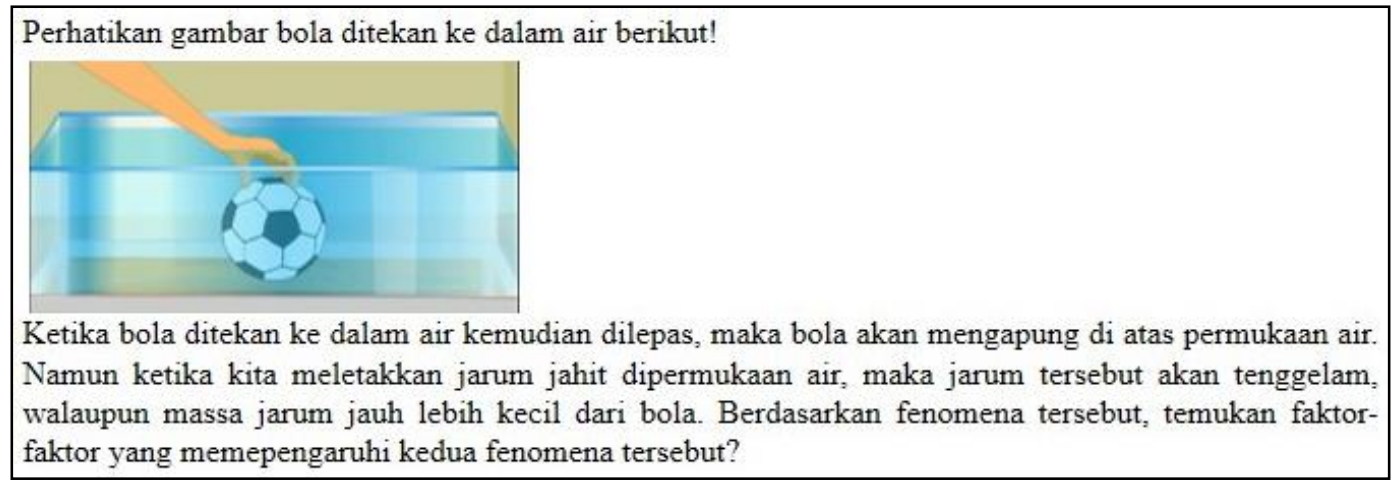

\section{Gambar 2 Soal 1 Pemecahan Masalah Hukum Archimedes}
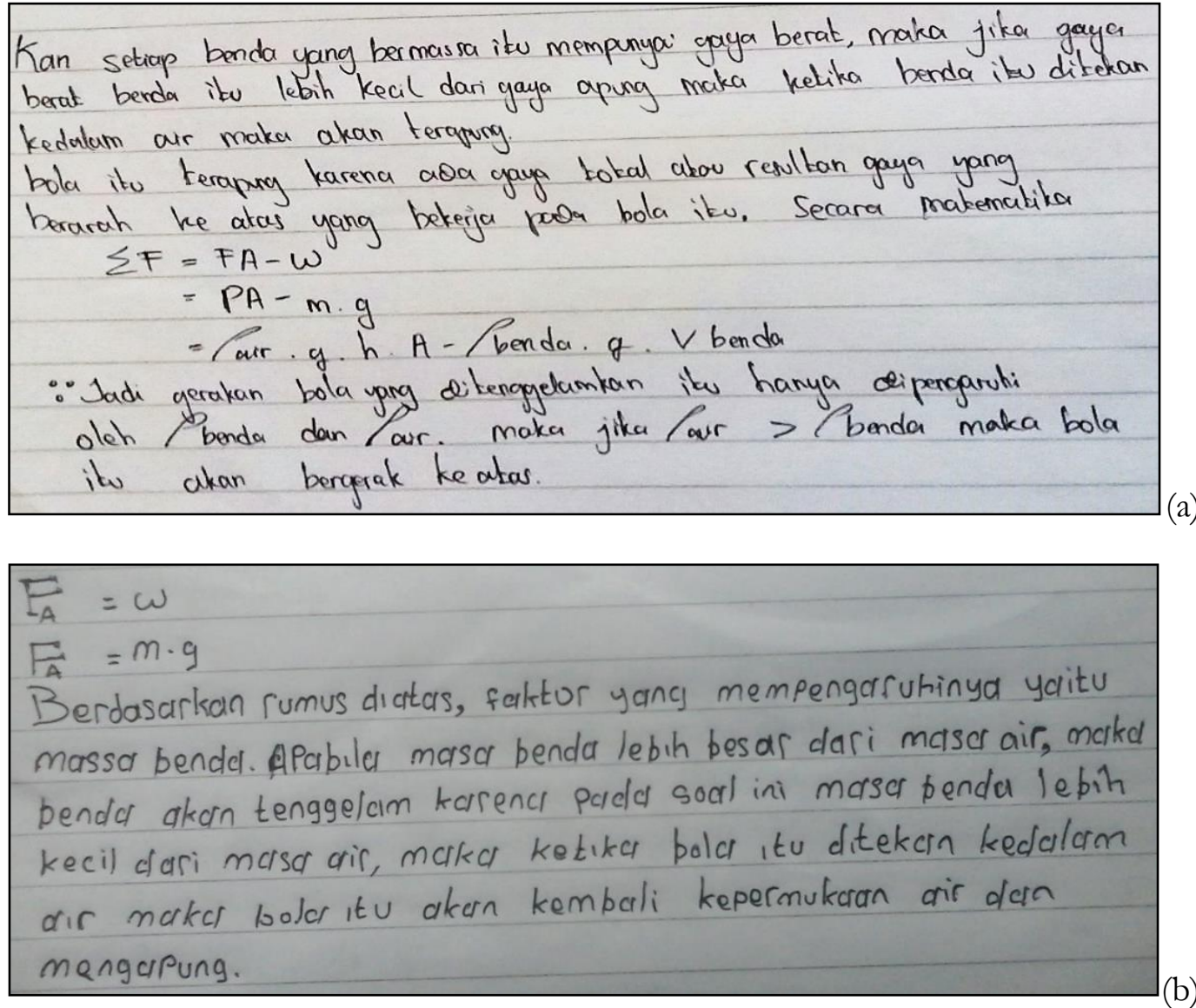

\section{Gambar 3 Hasil Pemecahan Masalah Siswa Soal 1 (a) Kategori Expert (b) Kategori Novice}

Hasil pemecahan masalah siswa pada gambar 3a tampak bahwa siswa memecahkan masalah dengan sistematis. Proses pemecahan diawali dengan mendeskripsikan masalah secara kualitatif berdasarkan konsep, yaitu dengan membuat deskripsi jika berat benda lebih kecil dari gaya apung maka benda tersebut akan terapung 
dipermukaan air. Hal ini menunjukkan bahwa siswa mampu menerapkan useful description dengan baik. Selanjutnya untuk mempermudah pemecahan masalah, siswa menentukan pendekatan fisika yang sesuai dengan masalah yaitu bola tersebu terapung karena adanya resultan gaya yang bekerja pada benda yang berarah ke atas yang mencirikan physics approach. Langkah-langkah penyelesaian yang dilakukan siswa sangat tampak bahwa siswa menerapkan konsep dalam menerapkan masalah. Hal ini dibuktikan dengan kebenaran penerapan rumus fisika yang digunakan terkait konsep gaya apung yang mencirikan spesific application of physics. Diakhir penguraian jawaban, terlihat bahwa siswa membuat suatu kesimpulan dari hasil yang ditemukan bahwa benda yang ditenggelamkan di dalam air hanya dipengaruhi oleh massa jenis benda dan massa jenis air yang merupakan bagian dari logical progression. Proses pemecahan masalah yang dilakukan siswa secara garis besar mencirikan perilaku expert.

Sedangkan hasil pemecahan masalah siswa pada gambar 3b tampak bahwa siswa tidak memulai menyelesaikan masalah dengan membuat deskripsi kualitatif dan cenderung menggunakan persamaan matematis diawal pemecahan serta langsung menentukan faktor yang mempengaruhi benda yang dicelupkan di dalam air yaitu berat benda. Proses pemecahan masalah yang dilakukan tampak bahwa siswa tidak mengenali masalah berdasarkan konsep yang mendasar dan tanpa melakukan evaluasi terhadap solusi. Proses pemecahan yang dilakukan siswa secara garis besar mencirikan perilaku novice.

Selanjutnya contoh soal 2 hukum Archimedes serta hasil pemecahan masalah expert problem solver dan novice problem solver ditunjukkan pada gambar 4 dan gamba 5 . Pada soal 2, siswa diminta memecahkan permasalahan terkait peristiwa mengapung dan tenggelamnya suatu benda. 


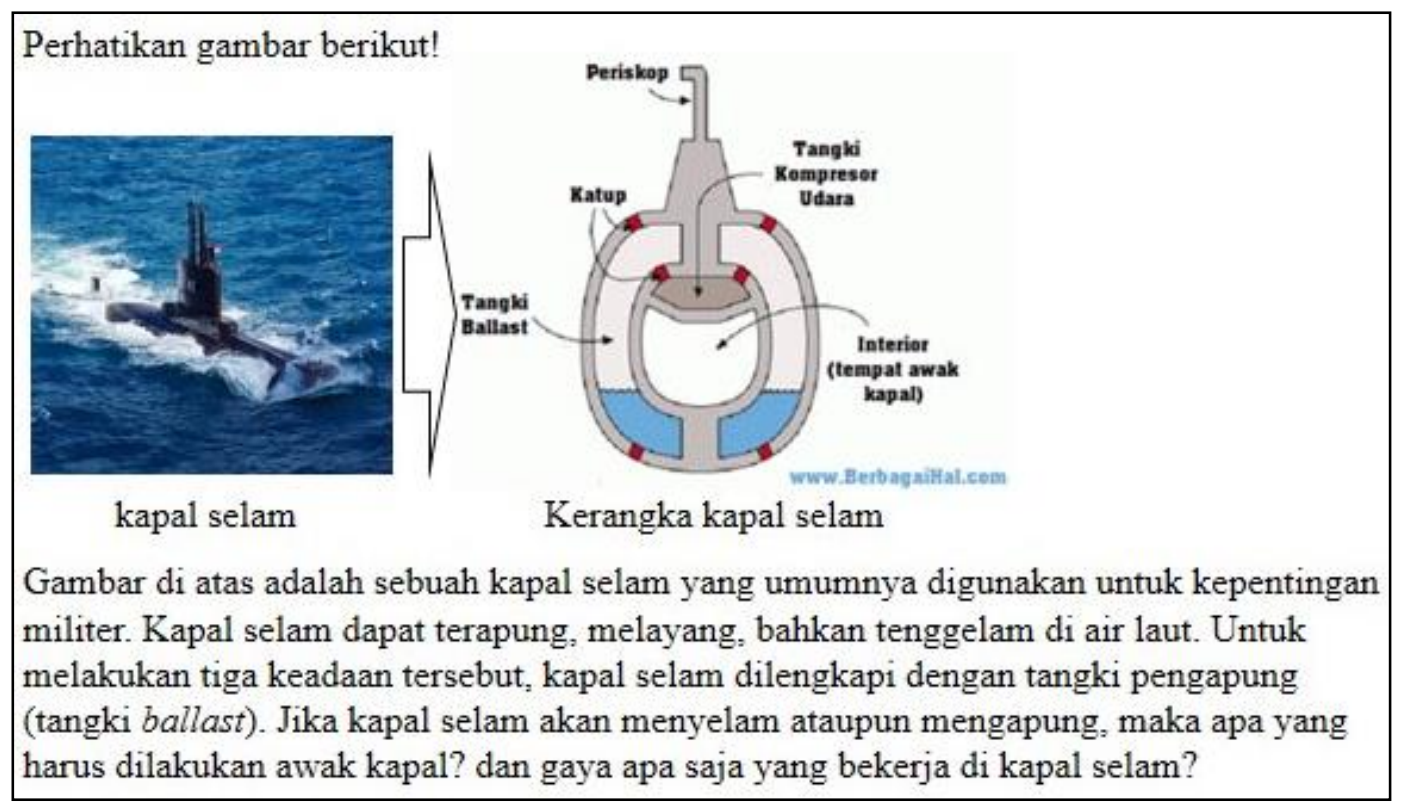

Gambar 4 Soal 2 Pemecahan Masalah Hukum Archimedes
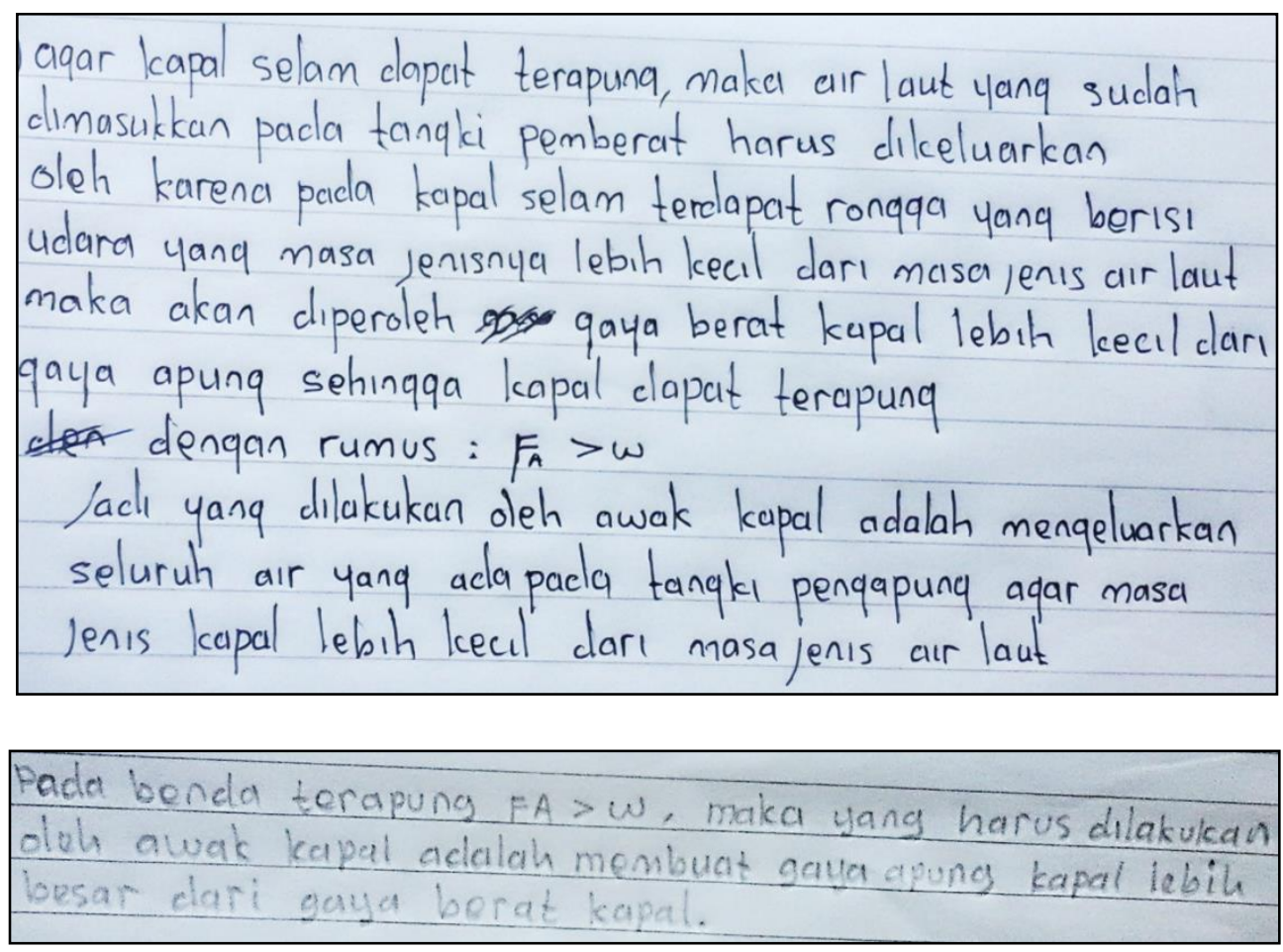

Gambar 5 Hasil Pemecahan Masalah Siswa Soal 2 (a) Kategori Expert (b)

\section{Kategori Novice}

Hasil pemecahan masalah siswa pada gambar 5a tampak bahwa siswa memecahkan masalah dengan sistematis. Proses pemecahan diawali dengan 
mendeskripsikan masalah secara kualitatif berdasarkan konsep, yaitu dengan membuat deskripsi agar kapal selam dapat terapung maka air laut yang sudah dimasukkan pada tangki pemberat harus dikeluarkan. Temuan ini menunjukkan bahwa siswa mampu menerapkan useful description dengan baik. Selanjutnya untuk mempermudah pemecahan masalah, siswa menentukan pendekatan fisika yang sesuai dengan masalah yang dipecahkan yaitu pada kapal selam terdapat rongga yang berisi udara yang massa jenisnya lebih kecil dari massa jenis air laut maka akan diperoleh gaya berat kapal lebih kecil dari gaya apung sehingga kapal dapat terapung yang mencirikan physics approach. Langkah-langkah penyelesaian yang dilakukan siswa sangat tampak bahwa siswa menerapkan konsep dalam menerapkan masalah. Hal ini dibuktikan dengan kebenaran penerapan rumus fisika yang digunakan terkait konsep gaya apung yang mencirikan spesific application of physics. Selanjutnya diakhir penguraian jawaban, terlihat siswa membuat kesimpulan dari hasil yang ditemukan bahwa yang harus dilakukan oleh awak kapal adalah mengeluarkan seluruh air yang ada pada tangki pengapung agar massa jenis kapal massa jenis kapal lebih kecil dari massa jenis air laut. Hal ini mencirikan bahwa siswa telah melakukan logical progression dengan baik. Proses pemecahan masalah yang dilakukan siswa secara garis besar mencirikan perilaku expert.

Sedangkan hasil pemecahan masalah siswa pada gambar $5 \mathrm{~b}$ terlihat bahwa siswa tidak mulai menyelesaikan masalah dengan membuat deskripsi kualitatif dan cenderung menggunakan persamaan matematis diawal pemecahan serta langsung ketujuan dengan mengatakan bahwa yang harus dilakukan oleh awak kapal adalah membuat gaya apung kapal lebih besar dari gaya berat kapal. Proses pemecahan masalah yang dilakukan tampak bahwa siswa tidak mengenali masalah berdasarkan konsep gaya apung yang mendasar dan tanpa melakukan evaluasi terhadap solusi yang dihasilkan. Proses pemecahan yang dilakukan siswa secara garis besar mencirikan perilaku novice.

Berdasarkan hasil test dan wawancara setiap butir soal, menunjukkan bahwa proses pemecahan masalah hukum archimedes yang dilakukan siswa terdiri dari dua kategori yaitu expert dan novice. Hasil penelitian ini menunjukkan bahwa siswa expert dan novice memiliki perbedaan dalam menggunakan pengetahuan, menghubungkan 
satu konsep dengan konsep, serta strategi yang digunakan dalam memecahkan masalah hukum archimedes. Temuan ini sejalan dengan penelitian yang dilakukan Erceg dkk (2011) yang menyatakan bahwa siswa expert dan novice memiliki perbedaan yang signifikan dalam menggunakan strategi yang digunakan saat memecahkan masalah.

Ketika berhadapan dengan masalah soal 1, expert problem solver melakukan serangkaian analisis kualitatif dari permasalahan dan mengidentifikasi prinsip-prinsip dasar dan konsep yang berkaitan. Mereka mengorganisir pengetahuan mereka dalam cara yang sangat terstruktur dan sangat berkaitan sehingga dapat diterapkan dalam situasi yang berbeda. Analisis kualitatif dilakukan dengan menggambarkan keadaan benda yang ditekan kedalam air jika gaya berat benda lebih kecil dari gaya apung. Hal ini dilakukan untuk menganalisis keterkaitan gaya berat benda dengan besar gaya apung yang dialami benda. Temuan ini sejalan dengan penelitian Yuliati (2016) yang menyatakan bahwa siswa expert cenderung mencari keterkaitan antar konsep sebelum menyelesaikan masalah, ${ }^{12}$ karena analisis awal ini akan memudahkan siswa untuk menentukan bagaimana masalah akan dipecahkan serta dapat menentukan cara yang tepat untuk menyelesaikan masalah. ${ }^{13}$

Berbeda dengan expert problem solver, novice problem solver sebagian besar berfokus pada manipulasi persamaan yang didapatkan dari awal proses pemecahan masalah. Mereka berusaha untuk mencapai solusi sesegera mungkin menggunakan serangkaian persamaan matematika dan akhirnya mengalami kesulitan dengan cepat. Kesulitan tersebut dialami karena minimnya penggunaan pengetahuan konseptual dan juga dorongan pada proses untuk mendapatkan jawaban. Hal ini sejalan dengan penelitian Ding et al. (2011) dan Docktor and Mestre (2014) yang menyatakan bahwa novice problem solver mulai memecahkan masalah dengan menuliskan persamaan yang sesuai dengan pernyataan pada informasi masalah. ${ }^{14}$ Selain itu novice problem solver lebih fokus pada nilai-nilai kuantitatif dalam informasi masalah. ${ }^{15}$

12 (Pendidikan, Yuliati, and Mufti 2016)

13 (Murray and Byrne 2013)

14 (Docktor and Mestre 2014)

15 (Ryan et al. - 2016 - Computer problem-solving coaches for introductory physics Design and usability studies(2).pdf n.d.) 
Sedangkan pada soal 2, expert problem solver melakukan serangkaian analisis kualitatif dari permasalahan dan mengidentifikasi prinsip-prinsip dasar dan konsep yang berkaitan. Mereka mengorganisir pengetahuan mereka dalam cara yang sangat terstruktur dan sangat berkaitan sehingga dapat diterapkan dalam situasi yang berbeda. Hal ini sejalan dengan hasil penelitian Walsh, Howard, and Bowe (2007) bahwa expert problem solver memiliki struktur pengetahuan yang sangat terorganisir sehingga expert problem solver mampu memecahkan masalah secara terstruktur berdasarkan konsep-konsep yang mendasari masalah yang dipecahkan. Analisis kualitatif dilakukan untuk menggambarkan struktur masalah yang akan dipecahkan, yaitu kapal selam memiliki tangki pemberat maka untuk mengapung air yang ada di dalam tangki harus dikeluarkan. Hal tersebut dilakukan untuk merepresentasi hubungan antara gaya berat kapal selam dengan gaya apung oleh zat cair. Hal ini sejalan dengan hasil penelitian Bagno and Eylon (1997) yang menyatakan bahwa diawal pemecahan masalah expert problem solver cenderung membuat representasi kualitatif yang bertujuan untuk menggambarkan masalah secara keseluruhan.

Berbeda dengan expert problem solver, novice problem solver cenderung tidak membuat deskripsi kualitatif terlebih dahulu sehingga kecenderungan memperoleh solusi yang salah. Hal ini karena novice problem solver cenderung memecahkan masalah dengan membuat representasi variabel yang diketahui dalam soal dan tanpa menganalisis masalah di dalam soal secara keseluruhan. ${ }^{16}$ Hal tersebut dilakukan karena kurang menguasai konsep. Sejalan dengan hasil penelitian Ceberio, Almudí, and Franco (2016) bahwa novice problem solver disebabkan oleh kurangnya penguasaan konsep yang dimiliki.

\section{KESIMPULAN}

Berdasarkan analisis hasil test dan wawancara dapat disimpulkan bahwa perilaku siswa dalam memecahkan masalah dibagi menjadi dua kategori yaitu expert dan novice. Siswa expert dan novice memiliki perbedaan dalam memecahkan masalah hukum Archimedes. Siswa expert mulai memecahkan masalah dengan

\footnotetext{
16 (Bagno and Eylon 1997)
} 
mendeskripsikan masalah secara kualitatif, memilih konsep fisika yang tepat dan prinsip yang akan digunakan dalam memecahkan masalah, serta mengaplikasikan konsep fisika yang tepat dan prinsip yang digunakan dalam menemukan solusi dan mengevaluasi hasil pemecahan diakhir. Sedangkan kategori novice, mereka cenderung tidak mendeskripsikan masalah secara kualitatif diawal pemecahan, namun langsung menentukan persamaan dan tidak mengevaluasi hasil pemecahannya, sehingga kecenderungan memperoleh solusi yang salah.

Berdasarkan hasil penelitian yang telah disimpulkan dan dalam upaya meningkatkan kemampuan pemecahan masalah siswa, disarankan kepada peneliti lain untuk mengadakan penelitian lanjutan menggunakan model pembelajaran yang dapat melatih dan memfasilitasi siswa dalam memecahkan masalah seperti model problem based learning, pembelajaran STEM berbasis masalah, pembelajaran berbasis projek terintegrasi STEM, dan inquiry agar dapat membantu siswa novice menjadi expert.

\section{DAFTAR PUSAKA}

Aini, Nita Nur, Sentot Kusairi, and Markus Diantoro. 2017. "Penguasaan Konsep Fluida Statis dengan Penilaian Formatif." (2012): 1377-87.

Bagno, Esther, and Bat-sheva Eylon. 1997. "From Problem Solving to a Knowledge Structure: An Example from the Domain of Electromagnetism From Problem Solving to a Knowledge Structure: An Example from the Domain of Electromagnetism.” (April 2015).

Ceberio, Mikel, José Manuel Almudí, and Ángel Franco. 2016. "Design and Application of Interactive Simulations in Problem-Solving in University-Level Physics Education." Journal of Science Education and Technology 25(4): 590-609.

Chen, Ying, Paul W. Irving, and Eleanor C. Sayre. 2013. "Epistemic Game for Answer Making in Learning about Hydrostatics." Physical Review Special Topics Physics Education Research 9(1): 1-7.

Ding, Lin, Neville Reay, Albert Lee, and Lei Bao. 2011. "Exploring the Role of Conceptual Scaffolding in Solving Synthesis Problems." Physical Review Special Topics - Physics Education Research 7(2): 1-11.

Docktor, Jennifer L. et al. 2016. "Assessing Student Written Problem Solutions: A Problem-Solving Rubric with Application to Introductory Physics." Physical Review Physics Education Research 12(1): 1-18.

Docktor, Jennifer L., and José P. Mestre. 2014. "Synthesis of Discipline-Based Education Research in Physics." Physical Review Special Topics - Physics Education Research 10(2): 1-58. 
Dwi, I M, H Arif, and K Sentot. 2013. "Pengaruh Strategi Problem Based Learning." 9(5): 8-17.

Erinosho, Stella Y. 2013. "How Do Students Perceive the Difficulty of Physics in Secondary School ? An Exploratory Study in Nigeria." 3(3): 1510-15.

Journal, International, and Technology Volume. 2017. “5 12017 2147-611x.” 5(1).

Murray, M Aisling, and Ruth M J Byrne. 2013. "Cognitive Change in Insight Problem Solving: Initial Model Errors and Counterexamples Cognitive Change in Insight Problem Solving: Initial Model Errors and Counterexamples." (December 2014): 37-41.

Pendidikan, Jurnal, Lia Yuliati, and Nandang Mufti. 2016. “Tersedia Secara Online EISSN: 2502-471X Pola Penalaran Ilmiah dan Kemampuan Penyelesaian Masalah Sintesis Fisika." : 2013-16.

Purwanto, Rudi, and Lia Yuliati. 2017. "Eksplorasi Kemampuan Pemecahan Masalah Siswa SMA Pada Materi Fluida Statis.” 2(2010): 286-92.

Riantoni, C., L. Yuliati, N. Mufti, and N. Nehru. 2017. "Problem Solving Approach in Electrical Energy and Power on Students as Physics Teacher Candidates." Jurnal Pendidikan IP A Indonesia 6(1): 55-62.

Rosengrant, David, Alan Van Heuvelen, and Eugenia Etkina. 2009. "Do Students Use and Understand Free-Body Diagrams?” Physical Review Special Topics - Physics Education Research 5(1): 1-13.

"Ryan et Al. - 2016 - Computer Problem-Solving Coaches for Introductory Physics Design and Usability studies(2).pdf."

Wagner, Doris J., Elizabeth Carbone, and Ashley Lindow. 2014. "Exploring Student Difficulties with Buoyancy." (may): 357-60.

Walsh, Laura N., Robert G. Howard, and Brian Bowe. 2007. "Phenomenographic Study of Students' Problem Solving Approaches in Physics." Physical Review Special Topics - Physics Education Research 3(2): 1-12. 